\title{
Más allá de los estantes vacíos: Alcances desde la autoetnografía sobre el consumo de papel higiénico en Lima Metropolitana durante la pandemia de COVID-19
}

\section{Marcelo Armas Gonzales}

Estudiante de Ciencia Política de la Universidad Antonio Ruiz de Montoya (UARM). e-mail: marce.armasgonzales@gmail.com

\section{Renzo Egúsquiza Giove}

Estudiante de Ciencia Política de la Universidad Antonio Ruiz de Montoya (UARM). e-mail: renzo.eggi@gmail.com

\section{Resumen}

En este artículo se analizarán las compras masivas de un producto básico como el papel higiénico y la repercusión de este comportamiento en la sociedad dentro la coyuntura actual de la COVID-19 en Lima, Perú. Para ello, nos basamos en conceptos como el miedo líquido, la antropología de consumo y la psicología de masas para que nos ayuden a sustentar lo siguiente: detrás de un comportamiento aparentemente irracional, existe un aparato cultural determinado por el modelo neoliberal que promueve la obtención de bienes materiales como un proceso de satisfacción y búsqueda de estabilidad inconsciente. Asimismo, nos valdremos del método autoetnográfico para lograr un mayor involucramiento con el fenómeno. De esa manera, las conclusiones estarán ligadas a nuestra percepción respecto a lo que estas prácticas generan. Al seguir estos hallazgos, se puede observar la necesidad de que se aborde este tema en futuras investigaciones posteriores sobre la coyuntura de la COVID-19.

\section{Palabras clave}

Autoetnografía, miedo, sociedad, consumo, COVID-19. 


\title{
Beyond the empty shelves: Scopes from autoethnography on the consumption of toilet paper in Metropolitan Lima during the COVID-19 pandemic
}

\author{
Marcelo Armas Gonzales \\ Political Science student at the Antonio Ruiz de Montoya University (UARM). \\ e-mail: marce.armasgonzales@gmail.com \\ Renzo Egúsquiza Giove \\ Political Science student at the Antonio Ruiz de Montoya University (UARM). \\ e-mail: renzo.eggi@gmail.com
}

\begin{abstract}
In this article, we will analyze the massive purchases of basic products such as toilet paper, as well as the repercussions of these behaviors in society in the current COVID-19 situation, in Lima, Perú. For this purpose, we rely on concepts such as liquid fear, consumer anthropology and crowd psychology, to help us support the following thesis: behind an apparently irrational behavior, there is a cultural apparatus determined by the neoliberal model that promotes the obtaining of material goods as a process of satisfaction and search for unconscious stability on individuals. Likewise, we will use the autoethnographic method to achieve greater involvement with the conclusions derived from the study, mainly those related to the selfperception that these excessive consumption practices generate in others. Following these findings, they confirm the need to address this issue in future research on the COVID-19 situation.
\end{abstract}

\section{Keywords}

Autoethnography, fear, society, consumption, COVID-19. 


\section{Introducción}

A mediados de marzo del año pasado, antes de la confirmación del primer caso de COVID-19 en el Perú, fuimos testigos del abarrotamiento en centros comerciales por la compra de productos sanitarios, en particular, de papel higiénico. Las largas colas, los carritos de compras desbordados y las estanterías vacías reflejaban una serie de conductas que no han sido insólitas; sino más bien sucesos repetitivos en esta pandemia. Estos actos reflejan una configuración cultural que sobrepasa los alcances teóricos de las leyes tradicionales del mercado.

En este sentido, la presente investigación se enfoca principalmente en dar algunos alcances analíticos para comprender a nivel social y cultural las compras masivas de grupos de individuos en un contexto urbano; específicamente, Lima Metropolitana. La selección de esta localidad se debe a que es el lugar donde ambos investigadores residimos y es allí que desarrollaremos un método autoetnográfico. Utilizamos este método para aportar mediante nuestras experiencias subjetivas, ya que a partir de la reflexión de nuestros sesgos iniciales se pudo desprender el análisis antropológico que ayudó a la elaboración del artículo. Al tomar en cuenta lo mencionado surgen las siguientes interrogantes: a pesar de que no conocemos con certeza los escenarios futuros, ¿cómo podemos explicar el desarrollo de este consumo en un contexto sociocultural, del cual se infieren ciertos análisis de mercado como un proceso no racional ${ }^{1}$ Por otro lado, ¿cómo las personas encuentran controlar la situación mediante la compra en grandes cantidades de bienes básicos, en este caso, el papel higiénico? ${ }^{2}$

Nuestra decisión de analizar este tema desde la antropología cultural se debe a que, como menciona Kottak (2011), está nos proporciona mayores alcances teóricos para entender los cambios significativos en la cultura; así como también el análisis de la psicología humana en el contexto de la variación social y cultural, como lo es precisamente la situación pandémica internacional que vivimos. Además, emplea explicaciones que se apoyan en asociaciones y teorías; estas últimas son más generales y sugieren o implican asociaciones y trata de explicarlas. En este plano conceptual, el consumo de papel higiénico se ubica como uno de los fenómenos más enigmáticos y menos estudiados. Por último, es importante mencionar que la escritura de este artículo recae en motivaciones de compromiso social con la comunidad en la que ambos estamos situados. En otras palabras, nuestro estudio resulta socialmente pertinente al dilucidar qué elementos culturales explican las compras masivas de papel higiénico para desde allí lograr una compresión de las diversas conductas que emergen en momentos de crisis.

\footnotetext{
1 Es necesario, señalar que lo entendido en este contexto como proceso no racional lo detallaremos en líneas más adelante.

2 Los conocidos diarios peruanos Gestión (2020), El Comercio (2020) y La República (2020) han resaltado el análisis de especialistas que priorizan razones económicas para explicar la demanda del papel higiénico y su repercusión en el mercado. Este enfoque de análisis asume que una compra racional hace referencia a que la persona sabe para qué y por qué comprar determinado producto, siempre orientado a maximizar una utilidad-beneficio. Aquella noción forma parte de la teoría de la elección racional, la cual tomó notoriedad en la academia estadounidense como respuesta a la economía de bienestar a mediados del siglo XIX.
} 


\section{Antecedentes teóricos para un diagnóstico social}

Considerar que en el país se ha posicionado hegemónicamente la cultura occidental resulta cierto si usamos de sustento el ideal de desarrollo del libre mercado propuesto por la Escuela Austriaca de economía en el s. XX, fundada por Hayek, Robbins y Misses, los cuales tienen lineamientos que fomentan el consumo excesivo de bienes y servicios debido a la sobreproducción de ellos. El alcance de este ideal, a nivel social y cultural, termina por introducirse en nuestra sociedad moldeando nuestras interacciones de convivencia; así, podemos afirmar que también nos desarrollamos dentro de una sociedad de consumo, donde las relaciones de consumo se convierten en la principal fuerza que pone en movimiento a toda la sociedad. Aquellas relaciones tienden a no ser cuestionadas porque los lineamientos en que se desarrolla el libre mercado son considerados como preestablecidos, los cuales toman como procesos racionales al comportamiento social del consumo. De esta manera, definen lo racional como toda interacción social que esté basada en la lógica de optimizar los beneficios del mercado y a reducir los riesgos económicos.

En el marco neoliberal se limitan las capacidades de acción de la administración pública para el diseño y configuración de ciudades. Esto se da porque los agentes económicos con la solvencia para realizar grandes proyectos se encuentran en su mayoría en el sector privado (Minguet, 2015). En consecuencia, los criterios neoliberales son trasladados a la planificación urbana como una realidad irrevocable $\mathrm{y}$, posteriormente, son transmitidos a los ciudadanos como un modelo de desarrollo urbano deseado. Este sistema significa la aniquilación de lo público y lo político por la imposibilidad de la discusión o el disenso en materia de desarrollo, a favor de la "mera gestión" o "management" que es herencia de la cultura comercial preponderante. Las consecuencias de este modelo es la sustitución del espacio público por el privado, el cual está fuertemente materializado en la figura del centro comercial que camufla su fin primordial: el consumo. Asimismo, al fortalecerse esta visión neoliberal en donde solo el modo de producción capitalista y las políticas de austeridad económica producen bienestar, se prepondera la excesiva autoproducción de los individuos a través de las relaciones que el mismo mercado condiciona como la propiedad privada y libertad de comercio (Harvey, 2005), esto genera que los individuos piensen en velar por sí mismos ya que no existen instituciones o mecanismos que lo apoyen; precisamente, esto se relaciona al concepto de 'tecnologías del yo' (Foucault, 1990).

Según Foucault (1990) aquel concepto se refiere a una forma de autorrealización del individuo por medio de operaciones sobre el cuerpo y el alma que intentan moldear los pensamientos y conductas "por cuenta propia o con la ayuda de otros, [...], obteniendo así una transformación de sí mismos" (p.48) para alcanzar cierto bienestar o superación propia. Siguiendo a Foucault, aquellos recursos e instituciones que ha creado el mercado serían descritos como dispositivos de biocontrol -el diseño urbano está ampliamente orientado en ese sentido con los supermercados y centros comerciales- que incitan al consumo y mientras más inmersos estamos a ellos, 
más internaliza la visión individualista. Sin embargo, la situación pandémica ha demostrado la ineficiencia del orden establecido por el mercado y le ha presentado restricciones a su desenvolvimiento. Esto también cala en la población que está acostumbrada al frenesí del crecimiento económico; lo cual resulta en escenarios trágicos de sufrimiento y muerte como ha sucedido históricamente con las crisis económicas. Eso nos motiva a ir más allá de la mirada individualista y economicista del problema.

En la visión economicista austriaca, mencionada al comienzo, se reducía los comportamientos sociales a su aspecto económico, ya que eso explica las variaciones de demanda de un producto como una situación natural en el mercado, con lo cual pretende justificar los desbalances en el consumo. No obstante, según Narotzky (2004), la respuesta del consumidor no puede ser diagnosticada como una externalidad o una simple conducta irracional de compra. Aquel proceso mediante el cual la persona adquiere un producto tiene un orden simbólico y transferible que va más allá del carácter instrumental. Esto es porque lo que se consume cuenta con un "código especial determinado e impuesto por las racionalizaciones del consumidor, que responden a lo que su entorno le determina, es decir, la cultura" (Valverde, 2004, p. 110).

Aunque, consideramos que el sujeto no está irremediablemente determinado a desarrollar patrones de consumo de acuerdo al tipo de sociedad en la que se desenvuelve, nos animamos a atribuirle siempre una capacidad de agencia, pero desde un enfoque relacional ${ }^{3}$. Es decir, aunque el consumo es parte de la competencia cultural de todo sujeto, ponerlo en práctica y la elección de los objetos consumidos guarda una racionalidad o emocionalidad subjetiva. (Chomsky 1972, p. 238 citado en Valverde, 2004, p.112). Por consiguiente, las prácticas de consumo quedan a la contingencia de otros elementos, tales como la capacidad reflexiva de cada individuo, en la que determina cuánto de esa influencia cultural pone en práctica, así como cuán influenciado por esas instituciones culturales está un sujeto dentro de una nación. Lo que queremos rescatar es la capacidad que tienen las instituciones culturales, en sociedades como las descritas anteriormente, para influir en el comportamiento de sus integrantes.

Para corroborar esta concepción - de que la obtención de productos está influenciada por instituciones culturales- debemos indagar en la naturaleza del consumo mismo. Para ello, corresponde abocarnos a una concepción acerca del consumo menos enfocada en el individuo. Es decir, aproximarnos a una que sea capaz de entender sus variedades o especificidades dentro de un contexto cultural y a nivel colectivo.

\footnotetext{
Emirbayer (1998) sugiere que a las diversas unidades empíricas de análisis se les tiene que buscar un sentido considerándose inscritas en configuraciones relacionales y no como unidades discretas predeterminadas. Así, la agencia ya no se asocia simplemente a una capacidad intencional medios-fines, sino a una manera de experimentar el mundo, inscrita temporal e históricamente. Esto les permite a los actores sociales "apropiarse, reproducir e innovar ciertas categorías sociales y condiciones de acción de acuerdo a sus ideales colectivos e individuales, así como a sus intereses y compromisos.” (p. 1143).
} 
En esta línea, partiremos entendiendo al consumo como "un hecho social capaz de generar representaciones colectivas" (Durkheim, 1970 citado en Guglielmucci, 2015). En ese sentido, estas representaciones forman parte del conocimiento y el sentido común por haber sido legadas al individuo de una generación a otra, por lo cual, no puede encontrar su explicación exclusivamente dentro de la individualidad, sino que es siempre dependiente de la colectividad con la que se relaciona. Además, en contraposición al consumidor visto enteramente como objeto de la psicología individual, Douglas (1996) nos ayuda a ubicarlo como un actor que -aunque se desenvuelve por una racionalidad subjetiva y específica- se expresa mediante el acto de consumo a través del cual busca inscribirse, integrarse y ser concebido (en un juego relacional de percepciones); mientras sigue los patrones de consumo alineados a su marco cultural. Por tanto, no se puede entender la acción individual del consumo sin un marco cultural múltiple.

Luego, para entender a una sociedad en la que imperan las dinámicas de consumo, a continuación, abordaremos ciertas aproximaciones desde la antropología; así como desde otros enfoques desde las Ciencias Sociales. Es necesario señalar que el mismo consumo abrió un campo de investigación dentro de la antropología como disciplina; específicamente, a inicios del siglo XX con el auge de la producción industrial en serie, también llamada "fordismo" (Miller 1995, p.153). Para Miller (1995) ha sido circunstancial que la aceleración de esta nueva forma de producción también haya transformado los estudios sociales del consumo y se haya constituido como un nuevo campo de estudio dentro de la antropología, a la par de la antropología del parentesco y antropología lingüística. Respecto a las dinámicas de consumo en concreto, este mismo autor ha desarrollado tres formas de aproximación que pueden ser complementarias entre sí: en primer lugar, una orientación basada en las lógicas del mercado; en segundo lugar, las prácticas de mediación comunicativa, en la que analiza la relación entre bien y consumidor; y finalmente, las representaciones culturales, en las que explora el consumo como parte de determinados fenómenos sociales.

Es esta última orientación de las dinámicas de consumo la que consideramos pertinente y utilizaremos para el presente análisis, pues comprende desde las diferentes interacciones culturales entre los sujetos que se dan a partir del consumo hasta la representaciones simbólicas que se le atribuye a los productos consumibles. Según Miller (1995) desde una perspectiva estructuralista podríamos señalar que los bienes y servicios que los grupos de sujetos consumen, constituyen parte de una estructura social; además, sirve de modelo para la identificación cultural de cada individuo (Valverde, 2004).

Ahora, es importante definir los límites de análisis a los que se ciñe el estudio del consumo de un producto específico como lo es el papel higiénico. Este es un producto de aseo personal y de necesidad sanitaria que tiene muy pocos sustitutos en localidades urbanas para la función que sirve. Además, no tiene la cualidad de ser perecible, por lo que puede almacenarse en grandes cantidades sin riesgo a desperdiciarse. Si bien 
estas características sugieren que no sería nada extraño proveerse de este producto, no es sino por la coyuntura de incertidumbre, a causa del virus y el aislamiento, que su valor simbólico ${ }^{4}$ y la necesidad por obtenerlo se incrementa como consecuencia del miedo a la escasez. Es así que el miedo y la sensación de incertidumbre surgen como variables clave e importantes para analizar el cómo la obtención de este producto dota una estabilidad imaginaria a los consumidores.

Justamente en la obra Miedo Líquido (2007), Zygmunt Bauman se hace un planteamiento filosófico de las sociedades modernas y manifiesta que "los peligros que más tememos son inmediatos; comprensiblemente, también deseamos que los remedios sean inminentes, "soluciones rápidas" -como si pudieran comprarse fácilmente en un supermercado- que proporcionen alivio al momento, "como analgésicos listos para llevar" (p. 143). Esto centra nuestra atención en analizar la articulación del miedo con las costumbres y prácticas culturales en estas sociedades de consumo. En este sentido, la sensación de miedo ha sido un factor determinante en el desarrollo histórico de la humanidad.

Para el teólogo Estrada (2001) las creencias religiosas tienen una fuerte implicancia en la sensación del miedo a través de la historia, ya que en los rituales se puede desprender que el trasfondo del miedo en el ser humano se halla el cuestionamiento por la muerte. Si bien la filosofía platónica adopta la concepción de ser un meditatio mortis, el asombro ante la muerte precede al origen de la filosofía; de hecho, este se encuentra en la base de la misma cultura (Monteagudo, 1996). Se podría decir incluso que las diversas producciones culturales representan una manera de trascender nuestra tradición mortal, al configurarse como experiencias significativas ${ }^{5}$ (p. 145). Esto tiene sentido, ya que Lévi-Strauss (1949) sugiere que dentro de estos rituales religiosos se desarrolla un fenómeno de cura a través de la realización de ciertas acciones ceremoniales, esto puede comprenderse a partir del concepto de eficacia simbólica. Aquel concepto puede definirse como la conexión simbólica de prácticas de ciertos grupos humanos que transfieren la sensación de alivio a otros de un mismo contexto cultural. Por lo tanto, el estremecimiento amenazante por la finitud de la existencia se ha manifestado en diversas culturas y de distintas maneras: desde representaciones rupestres en las cuevas de Altamira hasta la incorporación soteriológica de la muerte en la tradición judeocristiana (Estrada, 2001). Desde la modernidad, la visión de la muerte se transformó completamente: las imágenes míticas como la Gorgona y Lucifer en la antigua cultura occidental fueron desplazadas por otras manifestaciones con nociones más científicas, como la guerra, el hambre, catástrofes naturales, las cuales tuvieron sus propios medios culturales para transmitir aquella sensación de

\footnotetext{
4 Concepto derivado de la teoría de industrias culturales (Adorno y Horkheimer), donde el valor escapa de una lógica económico-política. En cambio, este se produce en un sistema de intercambio de signos y significaciones, donde adquieren un sentido más allá de su utilidad o de su equivalencia objetiva.

5 Monteagudo se refiere a que la experiencia debe ser valiosa e imbricarse en la historia del protagonista para que la vivencia adquiera sentido para la persona. Únicamente si la persona vislumbra este significado, puede tomar la decisión de asimilar su contenido; de ello la necesidad de que sea significativa.
} 
alivio con bases científicas. En ninguna dimensión social las experiencias de la vida humana han tenido garantía de "una protección infalible contra los golpes del destino" (Bauman, 2007, p. 172). Precisamente, el miedo surge de estas situaciones de infortunios imprevisibles, de incertidumbres que no podemos controlar, en las que el individuo está desprovisto de un orden mayor que garantice su integridad; por ello, la existencia de manifestaciones culturales a partir de la 'eficacia simbólica' intentan transmitir alivio y dar la sensación de equilibrio en aquellos contextos de incertidumbre.

La falta de previsibilidad de un futuro inmediato y la debilidad estructural que disipa las certezas sobre el devenir impiden a los individuos tener seguridad ante las amenazas que representa el rigor cotidiano. De esta manera, una situación pandémica como la que vivimos que materializa los temores más profundos sobre la condición humana de mortalidad, se refleja en la exacerbación de ciertas conductas como el comportamiento desmedido de consumo y la falta de empatía y recelo con los otros. Ahora bien, este tipo de comportamientos no necesariamente son exteriorizaciones conscientes de la sensación de miedo y estas tampoco originan una acción específica; es decir, el individuo no se dirige al centro comercial decidido a comprar desproporcionadamente. Siguiendo a Narotzky, se trataría de un proceso más complejo que incluye el acto simbólico de comprar por apaciguar aquella sensación de incertidumbre y miedo, esta sensación se transfiere a los individuos a través de las relaciones mediadas por el mercado, y, finalmente, la sensación de alivio se desarrolla al participar colectivamente en este fenómeno.

Es así que la dominación del modelo neoliberal ha moldeado consigo el desenvolvimiento cultural de los individuos y las relaciones sociales. Ante ello, como señala Bauman (2007), resulta congruente el hecho de que "necesitemos y deseemos vínculos sólidos y fiables más que en ninguna otra época anterior ( $p$. 94). A lo anterior se suma el tipo de amenaza que significa la posibilidad latente de contagiarse, puesto que el virus causante no es una materialidad percibible sensorialmente. Por ello, la persona se siente expuesta a un peligro desestabilizador al que no puede hacerle frente. Lo descrito solo incrementa la sensación de temor ante la incertidumbre, puesto que, "la pérdida de la imagen a la que adscribir el sentimiento, su ocultamiento y dispersión ha reforzado el potencial amenazador del miedo" (Antón, 2015, p. 269). En suma, las inseguridades y temores que causa la concepción de la muerte son aún más inquietantes dentro de un aparato cultural que ha reubicado los intereses y valores de la sociedad en obtención mercancías y propaganda (elementos que suelen mostrar su fragilidad en tiempos de crisis), y ante la concepción de una amenaza invisible que es incontrolable a través medios individuales como lo es la COVID-19.

Lo planteado anteriormente nos aproxima a poder comprender cómo se crea este recóndito y poco inspeccionado proceso de construcción de estabilidad en el imaginario cultural de la vida humana; específicamente, cuando afronta un 
hecho social que deja una sensación imprevisible por la inmediata proximidad de un acontecimiento indescriptible. Por consiguiente, es preciso exponer aquellas fisuras dentro de la estructura social que amenazan con resquebrajar la "solidez" del mercado. La visualización nítida de estas fisuras puede lograrse abordando el problema sobre los actos de los consumidores, al hacer un paralelo con la tipología de masas de Frederic Munné (1987) desde la psicología social.

En los círculos intelectuales del campo de la psicología social existe principalmente una polémica sobre el estudio de las colectividades o grupos sociales. Este debate articula aquella discusión principalmente a través de tres enfoques analíticos: el primero es la concepción de entidades distintas a los individuos y con la capacidad de estudiarlas como una unidad mental. El segundo enfoque propone algo similar, pero, sin desvincularlos de su comportamiento individual, comprende que los actos se originan por la exaltación instintiva de sentimientos reprimidos. Por último, está el enfoque que articula las perspectivas anteriores. A este último se le denomina como tipología de masas: una forma de comprender las colectividades sin perder el rastro de la identidad individual de los sujetos, y que considera la represión de los impulsos individuales que surgen de la necesidad de responder a un determinado conjunto de factores socioculturales propios de la comunidad (Munné, 1987). Nosotros nos apoyaremos en este último enfoque, puesto que tiene una aproximación conceptual que nos servirá para entender las complejas dinámicas de consumo en un estado de incertidumbre. Para Munné (1987), en situaciones de crisis las masas cuentan con funciones emotivas y cognitivas compartidas que le dan "sentido, descargando tensión, creando pertenencia, ofreciendo contención, proyectando estados de ánimo, introyectando creencias; es decir, comunicando, pensando, sintiendo y expresando" (Fernández 2012). La pandemia por el coronavirus nos expone ante "situaciones límite", en términos de K. Jaspers (1971). Estos son momentos en los que un hecho cotidiano nos hace conscientes de nuestra finitud y contingencia, nos retira del amparo con el que contábamos hasta ese instante.

Si adherimos estas concepciones con las de Bauman y Lévi-Strauss, podemos comprender cómo el comportamiento de los particulares se vuelve motivo de repetición y tendencia general; además, con una eficacia simbólica, para los individuos que conforman las masas. De esto se deriva que la psicología social explique comportamientos impulsivos de las masas como resultado de su propia composición cultural. Así, tenemos exacerbaciones de ansiedad colectiva y un hermetismo individualista ante el otro por el miedo a la enfermedad o compras exageradas por el síndrome FoMO, fear of missing out ${ }^{6}$ (Przybylski, Murayama, DeHaan \& Gladwell, 2013), ambos considerados como factores psicológicos participativos dentro de estas compras impulsivas.

\footnotetext{
6 Una patología psicológica vinculada al "temor a dejar pasar o perderse de algo que otros realizan, tienen, adquieren", relacionado a alguna tendencia o actividad particular. Su estudio indica que bajos niveles de satisfacción social están relacionados con altos niveles de FoMO.
} 


\section{Revelando las fisuras sociales desde un enfoque autoetnográfico}

La repercusión del confinamiento en las personas evidencia algunas inconsistencias que el modelo económico, configurador de la estructura social, ha disimulado en tiempos normales. Por tanto, nos orientamos a señalar que existen ciertas fisuras que son más evidentes en estas circunstancias y, para acceder a ellas, analizaremos algunos sucesos desde la antropología y la psicología social. Pero, al mismo tiempo, se nos dificulta no involucrar nuestras propias percepciones y experiencias. En otras palabras, es difícil mantener una postura completamente objetiva y neutral sobre la presente coyuntura de la pandemia de la COVID-19, puesto que nosotros también la hemos vivido. Por ello, consideramos conveniente relatar el proceso autoreflexivo sobre las compras masivas desde el método autoetnográfico.

El método autoetnográfico es un enfoque que reconoce y da lugar a la subjetividad, la emocionalidad y la influencia del investigador en su trabajo en determinados contextos socioculturales (Montagud, 2016). Se trata de una investigación narrativa que valoriza la experiencia del sujeto-investigador y conecta con su entorno social. Este modelo permite deslindarse de cierta petulancia de autoridad científica y revaloriza el carácter interpretativo de la verdad (Barthes, 1987; Ibañez, 1994; citados en Montagud, 2016) al involucrar las vivencias del propio investigador. Por ello, se destaca que el investigador dispone de información privilegiada sobre la comunidad de estudio por su condición de "nativo" o miembro del grupo estudiado. Por un lado, Ellis, Adam y Bochner (2015) denominaron a este tipo de narrativas como 'evocadoras'; eso significa que deben crear un efecto de realidad y mostrar la complejidad de las vivencias y conflictos humanos. De esa manera, permite invitar al lector a sentir la veracidad de sus historias, participando y adhiriéndose a ellas tanto moral, emocional, estética e intelectualmente. Además, el antropólogo Leon Anderson asevera que este enfoque posibilita superar las particularidades idiográficas (Montagud, 2016), lo que permite abordar temas más complejos.

Al seguir esta última propuesta metodológica y las orientaciones para el estilo narrativo en Bénard (2019), decidimos realizar un trabajo autoetnográfico para el curso de Antropología del Programa de Humanidades de la Universidad Antonio Ruiz de Montoya, utilizando una construcción interpersonal de testimonios a base de nuestras conversaciones cotidianas sobre la coyuntura y temas no rigurosamente académicos (Bénard, 2019; Ellis, Adam y Bochner, 2015). Esto ha sido construido con el propósito de invitar a los lectores a entender a través de nuestras historias el fenómeno y evocar el contexto de la COVID -19, para elaborar este artículo no solo se involucra nuestra lectura teórica, también nuestras percepciones personales ya que nos ayudó a reflexionar nuestras posturas con el tema (Montagud, 2016). Para ello, hemos seleccionando aquellos mensajes vinculados a nuestras preocupaciones para poder analizar nuestros sesgos iniciales a los acontecimientos vividos durante las compras masivas de papel higiénico en Lima Metropolitana, esto ayuda a 
crear una reflexión antropológica con ayuda de los alcances teóricos desarrollados anteriormente. Por otro lado, esto permite involucrar la percepción subjetiva del lector, invitándolo a participar de nuestra narrativa y reflexionar desde este análisis. Cabe añadir que aquellas conversaciones no tenían como objetivo ser fuente para un trabajo de investigación. Nuestra iniciativa a inicios del 2020 fue registrar percepciones y sensaciones propias respecto a procesos sociales, políticos, culturales, económicos y demás, escribiendo a manera de testimonio u opinión conforme iban desarrollándose diversos sucesos a nivel mundial, nacional, doméstica y personal, para compartirlas mutuamente a posteriori. Este material fue conveniente a sobremanera una vez descubierto el método autoetnográfico y una vez despertado el interés por el fenómeno de las compras masivas, decidimos ordenar algunas conversaciones significativas para que nuestros reiterativos cuestionamientos pudieran tener relación dialógica y fueron temporalizadas en el momento que desarrollamos el presente artículo ${ }^{7}$.

Antes de presentar nuestros testimonios, es esencial recordarle al lector que ambos autores somos estudiantes de la Universidad Antonio Ruiz de Montoya, del mismo grado y carrera profesional, ciencia política. Como futuros cientistas políticos, compartimos un amplio interés en comprender los fenómenos sociales de nuestros días. Esto es precisamente de lo que consta nuestra instrucción y formación dentro de la universidad: un ambiente donde las personas se piensan a sí mismas de cara a afrontar los problemas que devengan. En los siguientes párrafos, se detallan algunas reflexiones personales que no son más que una construcción breve de nuestras conversaciones temporalizadas en los días 14 y 15 de Marzo y del 20 al 22 de Abril, seleccionamos aquellas dos períodos porque en ellos se evidencia más el cambio de nuestra percepción en la elaboración de este trabajo.

Abril 2020, entrada de Renzo Egúsquiza: Las primeras sensaciones que puedo describir ante la situación de pandemia son mixtas. En primer lugar, nos estamos posicionando en un espacio temporal previo a la quincena de marzo, esto significa que el virus no tenía cifras preocupantes en el país. Por ello, puedo manifestar que las sensaciones de amenaza, miedo o peligro no tenían una manifestación consciente en mi persona. La percepción de la situación del virus en países como China o Italia me resultaba aún como un problema externo a mi realidad tangible. Sin embargo, la influencia de las redes sociales y las noticias por televisión, en donde pude observar las primeras medidas de cuarentena en las ciudades más afectadas por el virus, me hacían reflexionar sobre los condicionamientos de conducta social a los que obligaba esta situación pandémica, todavía sin una influencia emocional considerable sino desde una perspectiva externa.

Estos testimonios fueron registrados en notas y algunos surgieron hilando mensajes cotidianos intercambiados por ambos autores, aquellos testimonios solo comprenden las percepciones de los autores en el periodo de cuarentena de ese periodo del año 2020. 
Marzo 2020, entrada de Marcelo Armas: (Yo) también recuerdo la noche del sábado 14 de marzo, día anterior al anuncio de estado de emergencia, salí a Jirón de la Unión para acompañar a mi papá a pagar la tarjeta de un banco. Para regresar a mi distrito, San Juan de Lurigancho, por apuro recurrimos a utilizar taxi por aplicativo, en el camino de regreso me llamó bastante la atención el desplazamiento de algunos grupos de militares y policías, como si hubiera una manifestación cerca. En realidad, me llamó la atención porque de alguna manera cualquier persona que le llegan esos rumores típicos de mensajes llamados cadenas por redes sociales podía creer que eran ciertos. En el camino del Centro de Lima a mi distrito, sí o sí tenemos que ir por el Rímac y por la cercanía tanto de comunicación como de amistad, decidí escribirle a Renzo. Le escribí en tono de ironía que parece que tienen razón que el presidente va declarar ¡Toque de queda! porque había mucho movimiento policial.

He querido escribir este recuerdo, no porque ignore la posibilidad de un Estado de Emergencia, en mi caso ya conocía por medios de información la situación respecto a la COVID-19 en otros países. Tampoco quiero enunciar que me parecía evidente que se avecinaba una situación crítica en el sistema de salud. Lo hago con el simple hecho de mostrar que, a veces, tomamos estas cadenas de rumores como una noticia alarmista que es con la intención de provocar ciertas respuestas y comentarios sobre alguna vicisitud. Sin embargo, no todos tenemos las mismas impresiones con respecto a este tipo de información. En nuestro caso (Renzo y yo), no nos han provocado algún nivel de susceptibilidad al temor o alguna reacción de sorpresa.

Mayo 2020, entrada de Renzo Egúsquiza: No fue necesaria la medida de la inmovilización social para que mi percepción sobre el tema dé un giro. Menciono la inmovilización, como hito fundamental para la formación subjetiva de emociones, porque significa una ruptura drástica con el desenvolvimiento social al que uno está adecuado. Bauman (2007) en su representación de nuestra realidad actual donde, en contraposición a una sociedad sólida con bases fijas, definidas y perdurables, la sociedad líquida está en un vertiginoso cambio constante. Una transitoriedad ligada a factores culturales y económicos diluye la idea de fijación o establecimiento en espacio y tiempo, y genera así una incertidumbre por no saber cómo, por ejemplo, estará la economía al día siguiente, si podrá uno formar una familia, si dispondrá de trabajo o si podrá tener acceso a servicios básicos y de salud. Tampoco fue necesario tener un testimonio próximo sobre contagio o muerte; es decir, el primer desequilibrio no me fue producido precisamente por influencia directa del virus, sino por el comportamiento de las masas en los centro comerciales cercanos a mi hogar. No es pretencioso afirmar que coexistimos en un sistema que valora la posesión de capital y la acumulación de bienes (Narotzky, 2004). Esto se determina porque la organización de todos los elementos que involucra el consumo excede al objeto material. En cambio, se trata de un discurso coherente en su totalidad que vuelve a la materialidad significante de poder político, grupo cultural, clase social, etc. Se corresponde, por consiguiente, que las personas tengan atribuciones subjetivas añadidas a objetos de consumo de manera generalizada y que acudan a estos en una 
búsqueda por satisfacer necesidades más allá de las materiales. Ya había sido testigo por noticias internacionales del desabastecimiento de compras masivas en otros países; no obstante, -como mencioné anteriormente- no significaron una mayor trascendencia emocional. Con el anuncio de los primeros casos de la COVID-19 en el país, fui testigo, por medios periodísticos, de las aglomeraciones y tumultos en centros comerciales conocidos (Metro, Plaza Vea). Con ello, la realidad externa a la que hice referencia fue, en ese momento, lo más cercana posible a mi realidad cotidiana, más aún con las expresiones de preocupación por parte de mis padres: ¿Tan fea se está poniendo la situación?, ¿Ya no vamos a poder comprar?, ¿Tenemos todo lo necesario en casa?. Ellos bordean la tercera edad y por algunas enfermedades crónicas son considerados en mayor riesgo de mortalidad. Los carritos repletos de productos, las estanterías vacías de papel higiénico y desinfectantes materializaron sensaciones de inseguridad en mi persona al sentir que, eventualmente, podríamos vernos desprovistos de algún elemento vital.

Debo manifestar que esto fue desarrollado a un nivel reflexivo, motivado por un plano emocional. No significó que me sentí en la necesidad de acudir impulsivamente a un centro comercial para abastecernos de papel higiénico. Principalmente, porque presenciar conductas individualistas en el desorden, como el clásico: ¡sálvese quien pueda! te lleva a pensar prejuiciosamente y a categorizar estos actos como comportamientos irracionales, con los que no me identificaba. Es importante ver cómo nuestra identidad, está ligada mucho al desenvolvimiento y diferenciación respecto a los otros. Aunque existe una actitud común en la búsqueda por autodefinirse, consideramos que no existe tal cosa como una "identidad primera, íntima o pre-identitaria" que se cubre luego con la identidad social. En cambio, hay que considerar a la identidad social que nos es atribuida por los otros como elemento fundamental en la constitución mental que estructuramos sobre nuestro Yo (Rosset, 2007). Es un punto clave, puesto que el involucrarnos con las diversas conductas humanas nos ha puesto en un estado de atención, no solo a las voces de los consumidores, sino a sus mismos actos y expresiones. Este paso fue crucial para poder desprendernos, en parte, del etnocentrismo que nos hacía calificar a los compradores con actitudes bárbaras y comprender mejor su comportamiento porque identificamos que nuestra observación de la realidad está originalmente influenciada por nuestra circunstancia. No obstante, este fenómeno fue determinante para despertar la inquietud por entender qué procesos llevan a generar este tipo de comportamientos. Así, el estudio conductual de los otros exige salirme de mis consideraciones o de mis sesgos de distinción, para poder entenderlos y entenderme, como parte de una estructura cultural.

Sin fecha, entrada de Marcelo Armas: Casi a tres cuadras del lugar donde vivo, está el conocido supermercado mayorista Makro. Vivo en una vivienda multifamiliar. Usualmente, íbamos mi tío, mi abuelo y yo a comprar el saco de arroz y azúcar para el consumo del mes. Durante esta situación decidimos no ir, sobre todo por el caso de mi abuelo, ya que tiene noventa años y tiene historial médico. Frecuentemente, él y 
otros miembros de mi familia cuestionaban la decisión de no ir a hacer las compras: ¡Necesitamos abastecernos más porque nadie más nos va ayudar!, ¿Por qué no van (mi tío y yo) a comprar si se pueden acabar los productos de limpieza?, ¿Qué haría mal en ir ahora, ya que se agota el stock? Posteriormente, vimos ya innecesario salir y que podría ser riesgoso por tener que hacer las largas colas, que un poco más y saltaban hasta las pistas. Yo lo veía como una irracionalidad ir a comprar artículos como cerveza, gaseosas, y el famoso producto de esta cuarentena "el papel higiénico". El hecho de ver a gente comprando de esta manera me resultaba incoherente con las necesidades normales de una persona o familia. Esto se da porque en estas situaciones el objeto a ser consumido se personifica y, de esa manera, va generando su propio sentido. No responde a necesidades, sino es una práctica reiterativa incapaz de satisfacer, que se configura como un estilo de vida determinado por la posición sistemática de objetos/signos de consumo (Baudrillard, 1968; Bauman, 1997; Saavedra, 2007; Foucault, 1990). El consumo es el medio y fin de las sociedades donde impera el modelo neoliberal. De tal manera, el sistema económico es un elemento poderoso en la construcción de identidades así como un instrumento significativo de relacionarse en sociedad (Guglielmucci, 2015). Por otro lado, también fuimos testigos de aquellas largas colas, ya que exactamente a la vuelta de mi hogar se encuentra la avenida principal y está un banco conocido. Las colas para canjear los bonos o pagar las tarjetas llegaban y llenaban la pista frente a mi casa y el vecindario. Al inicio, las expresiones de mi familia (incluyéndome) fueron de hartazgo e incomodidad por la poca precaución y el tumulto. Por ello, no creo que este tema solo pueda ser visto como un simple fallo o un error lógico. No, claro que no; es más que eso. Las inseguridades que se mostraban en mis familiares se conectaban con lo que ocurría en nuestro alrededor. La presión de no poder comprar lo que todos tenían. De esto se desprende que las personas desarrollan sensaciones de satisfacción y estabilidad a través de la obtención de bienes materiales, sin que estos necesariamente garanticen la resolución de las incertidumbres anteriormente descritas. El papel higiénico se convierte en un símbolo de estabilidad y quien lo posea tendrá la sensación de que las cosas estarán bien en un futuro, de lo contrario la sensación de miedo se magnifica. Por ello, tiene sentido que este objeto asuma un impacto simbólico (Lévi-Strauss, 1949) al transmitir una sensación de 'normalidad' o 'cotidianidad' a aquellos que puedan adquirir este productor y formar parte de la práctica social; es decir, abastecerse del producto antes de que los estantes queden vacíos. Bajo estas premisas, la elección responsable de la preocupación por el otro ya no es parte de cuestiones morales, sino son vistas como parte de la competencia por autoimposición individual (Foucault, 1990), ya que se busca estar provistos de un bien determinado en la mayor medida de lo posible, sin importar cuánto queda para el resto.

\section{Breve análisis de lo anterior}

Coincidimos en que observar a las personas que generaron aglomeraciones en los centros comerciales y mercados mayoristas en Lima Metropolitana, sumado a la falsa imagen de desabastecimiento, había resultado en una categorización negativa hacia 
ellos, como incivilizados, faltos de educación e irracionales. Nuestra perspectiva de diferenciación respecto a ellos estuvo influenciada por nuestra posición y privilegios en relación a otros, así como la sensación de inseguridad que propiciaba la idea de quedarse desprovisto de insumos de primera necesidad. Posteriormente, pudimos detenernos a utilizar la mirada para hacer más una reflexión analítica y ya no un juicio de valor basado en el comportamiento de los demás, puesto que las personas no solo actúan guiados por sus anhelos individuales, sino también por la influencia de sus circunstancias.

Desde nuestra perspectiva, visualizar a personas desesperadas en supermercados, presenciar su miedo al desabastecimiento y al contagio, llegó a transmitirnos un grado de desasosiego. Esta sensación se disipó con las declaraciones del presidente y de las cadenas de supermercados que garantizaban que la cadena producción y distribución iba a funcionar sin problemas. Las compras masivas de papel higiénico tuvieron una corta duración de días; sin embargo, aún quedaba por comprender cuáles son los procesos psicológicos que los generan y reproducen.

\section{Conclusiones y reflexiones}

Este trabajo ha señalado algunas aproximaciones desde la antropología del consumo con ayuda de dos enfoques que hemos considerado pertinentes: el de representaciones simbólicas en el consumo (Miller, 1995) y la psicología de masas (Munné, 1987), para la comprensión de este hecho social en el contexto de la pandemia de la COVID-19. Por otro lado, era de suma necesidad la adopción del método autoetnográfico y ser objetos de estudio en nuestra condición de sujetos sociales que son afectados por el fenómeno. Cabe señalar que nuestros testimonios no son totalmente suficientes para describir todo el proceso detrás del fenómeno en cuestión; sin embargo, consideramos que hacer solo una descripción teórica también iba a ser insuficiente para alcanzar especificidades y el rol que juegan las subjetividades en el objeto de estudio. Por ello, consideramos incluir nuestros testimonios para intentar llenar la porosidad que resulta de una mera hipotetización. De esta manera, se justifica nuestra captación subjetiva en la que no mantenemos una postura netamente ajena al contexto. Con ello, es preciso mencionar que la finalidad de esta investigación es que sea funcional para ampliar los estudios sobre el comportamiento colectivo del consumo humano en una situación de pandemia y que pueda formar parte del registro de las percepciones de los sujetos de este contexto para el conjunto de investigaciones posteriores que se harán sobre la coyuntura de la COVID-19.

Podemos aseverar que, como lo planteamos en un inicio, las reacciones por comprar papel higiénico forman parte de un proceso cultural en la búsqueda de estabilidad, pero que funcionan bajo un marco neoliberal, especialmente en las relaciones del consumo y acumulación de mercancías. La influencia de la cultura en el consumo tiene un papel determinante en el comportamiento de la sociedad; en tanto las personas atribuyen una significación emocional al objeto y la acción relacionada 
a la compra; como también, tienden a replicar estos comportamientos como una respuesta a situaciones que desestabilizan su cotidianidad, como un reflejo por continuar con ese frenesí consumidor al que están acostumbrados. Esto quiere decir que los consumidores, al acudir a comprar papel higiénico de esa manera, no solo lo hacen luego de haber realizado un ejercicio reflexivo mediante el cual concluyen que mediante la compra, lograrán estabilidad; más bien, la obtención del papel higiénico por sí misma es un fenómeno simbólico. Así, la adquisición de este producto se da de manera casi mecanizada para poder tener la seguridad de que la persona no se verá desprovista de él, esto es motivado por querer adquirir la sensación de alivio y transmitir esa impresión de forma colectiva. Por ello, participar de las largas colas, tener las carretillas de supermercado llenas y dejar los anaqueles o estantes vacíos forman parte de este acto simbólico. Las imágenes de estas estanterías vacías tienen un poder replicador del miedo en la sociedad. Esto principalmente porque las personas asocian la idea de un supermercado bien surtido y la capacidad de desenvolverse en ellos, a través del consumo, a una noción de bienestar cotidiano. Esto es, que más allá de las estanterías vacías está el descalabro de las promesas ilusorias de seguridad y estabilidad con las que el modelo económico-cultural ha rellenado las porosidades de las sociedades modernas (términos de Bauman); y la crisis que vivimos, hace notar la vaporosidad de estas promesas. La estantería se vuelve un espejo frente al consumidor, y el reflejo exhibe los vacíos incómodos de la vida en estas sociedades de consumo, el horror vacui en su manifestación más contemporánea.

No obstante, observamos distintos niveles de tendencia a sentir la necesidad de acudir a los centros comerciales en Lima, en la medida en que el sujeto pueda hacer un ejercicio reflexivo y analítico entorno al fenómeno en cuestión, el cual permite en gran medida disipar las inseguridades que originan el impulso de replicar el comportamiento. Así, el ejercicio analítico y objetivo de la situación permitió disipar las inseguridades que sugerimos motivan a acudir a realizar compras desmedidas y en la misma línea impiden las calificaciones negativas hacia las personas que sí lo realizan, luego de comprender que estos sesgos parten de una visión economicista del consumo que reduce estos fenómenos al individualismo basado en la optimización de beneficios en una economía de mercado.

Del mismo modo, presenciar a otras personas haciendo compras apresuradas, estanterías vacías, largas colas, etc., transmite las inseguridades a los receptores de la información, lo que propicia, en muchos casos, que se acuda a estos centros de abasto con premura por miedo a verse desprovistos ante un futuro incierto, replicando el efecto. Finalmente, podemos contribuir más y tener mayor estabilidad actuando con fines colectivos, construir lazos de cooperación en comunidad en los momentos de crisis, y resistir la tendencia a actuar de manera individualista cuando nuestros actos afectan a la colectividad, ya que al final esto contribuye, como hemos mencionado, a la inestabilidad. 
Cabe añadir que descartamos una generalización en el comportamiento de las personas al ver estas situaciones. La construcción de una conversación desde el método autoetnográfico manifestó distintos niveles de abstracción y reflexividad ante este fenómeno en Lima Metropolitana, al tener como base el análisis teórico del comportamiento de los consumidores. Sin embargo, concluimos que es un elemento fundamental la preocupación e instrucción académica sobre los elementos sociales que involucran estos procesos para prevenir este tipo de acaparamiento del papel higiénico, como de calificar a los consumidores de manera negativa o despreciativa. De la misma manera y en un sentido complementario, estos fenómenos estimulan la investigación académica, con ello, la metodología autoetnográfica fue una fuente viable y enriquecedora, además de una alternativa propicia por la coyuntura de confinamiento. 


\section{Referencias bibliográficas}

Antón, F. (2015). Antropología del miedo. methaodos. Revista de ciencias sociales, 3(2), 262-275. https://doi.org/10.17502/m.rcs.v3i2.90

Baudrillard, J. (1968). El sistema socioideológico de los objetos y del consumo. Editorial Siglo XXI.

Bauman, Z. (1997). La postmodernidad y sus descontentos. Ediciones Akal.

Bauman, Z. (2007). Miedo líquido: La sociedad contemporánea y sus temores. Paidós.

Bénard, S. (2019). Autoetnografía. Una metodología cualitativa. Universidad Autónoma de Aguascalientes.

Coronavirus: compras desesperadas en los supermercados por COVID-19. (12 marzo de 2020). Diario La República. https://larepublica.pe/sociedad/2020/03/12/coronavirus-perucompras-desesperadas-en-supermercados-por-covid-19/

Coronavirus: ¿Por qué la gente compra papel higiénico? Opinan cuatro expertos. (12 de marzo de 2020). Gestión. https://gestion.pe/tendencias/coronavirus-por-que-la-gentecompra-papel-higienico-opinan-cuatro-expertos-noticia/

Ellins, C., Adams, T., y Bochner, A. (2015). Autoetnografía: un panorama general. Forum: Qualitative social research, 12(1), pp. 249-273. https://doi.org/10.17169/fqs-12.1.1589

Estrada, J. (2001). Razones y sinrazones de la creencia religiosa. Trotta Editorial.

Fernández, A. (2012). Psicología de masas, identidad social, epidemias y rumores: la influenza en México. Sociológica (México), 27(76), pp. 189-230. http://www.scielo.org.mx/ scielo.php?script $=$ sci_arttext\&pid=S0187-01732012000200006

Foucault, M. (1990). Tecnologías del yo y otros textos afines. Ediciones Paidós Ibérica

Guglielmucci, A. (2015). Publicidad, antropología y etnografía del consumo: coqueteos actuales entre disciplinas divergentes. Poliantea, 11(21), pp. 41-58. https://doi.org/10.15765/ plnt.v11i21.703

Harvey, D. (2005). Breve historia del neoliberalismo. Akal

Inga, C. (30 de marzo de 2020). Coronavirus genera cambios drásticos en el consumo, ¿cuáles son y hasta cuándo durarán?. Diario El Comercio. https://elcomercio.pe/economia/ dia-1/coronavirus-coronavirus-genera-cambios-drasticos-del-consumo-en-el-peru-cualesson-y-hasta-cuando-duraran-consumo- nielsen-kantar-arellano-opino-noticia/

Jaspers, K. (1988). Introducción a la Filosofía. Editorial Círculo de Editores.

Kottak, C. (2011). Antropología cultural. Mc-Graw Hill. 
Lévi-Strauss, C. (1949). Antropología estructural. Editorial Eudeba.

Minguet, J. (2015). Ciudad-consumo. Despolíticas de urbanismo comercial. dearq, 17 (1), pp. 14-25. http://dx.doi.org/10.18389/dearq17.2015.01

Miller, D. (1995). Consumo y Materias Primas. Annual Reviews Anthropology, 24 (1), 141161. https://doi.org/10.1146/annurev.an.24.100195.001041

Montagud, X. (2016). Analítico o evocador: una discusión olvidada en la autoetnografía. Forum: Qualitative social research, 17 (3), pp. 1-19. https://doi.org/10.17169/fqs17.3.2432

Monteagudo, C. (1996). La muerte y la filosofía. La temporalidad y la vida. Boletín del Instituto Riva-Agüero, (23), 141-154. http://repositorio.pucp.edu.pe/index/ handle/123456789/114409

Munné, F. (1987). Grupos, masas y sociedades. Promociones y Publicaciones de la Universidad de Barcelona.

Narotzky, S. (2004). Antropología económica: Nuevas tendencias de la antropología. Editorial Melusina.

Przybylski, A., Murayama, K., DeHaan, C., y Gladwell, V. (2013). Motivational, emotional, and behavioral correlates of fear of missing out. Computers in Human Behavior, 29(4), pp. 1841-1848. https://doi.org/10.1016/j.chb.2013.02.014

Rosset, C. (2007). Lejos de mí. Marbot Ediciones.

Saavedra, J. (2007). Adquirir la identidad en una comunidad de objetos: la identidad social dentro de la sociedad de consumo. Nómadas. Revista Crítica de Ciencias Sociales y Jurídicas, 16 (2). https://www.redalyc.org/articulo.oa?id=181/18153299026

Valverde, M. (2004). Un vistazo hacia la antropología del consumo. Cuadernos de Antropología (14), pp. 107-114. https://revistas.ucr.ac.cr/index.php/antropologia/article/ view/10798 